\title{
FOSTERING ADVANCED TEXTILE CENTERS THROUGH E-LEARNING IN MOROCCO AND JORDAN
}

\author{
RALUCA MARIA AILENI, LAURA CHIRIAC, RAZVAN ION RADULESCU \\ INCDTP, Lucretiu Patrascanu 17, sector 3, Bucharest, Romania, raluca.aileni@incdtp.ro
}

\begin{abstract}
This paper presents some aspects of the need for training and EU best practices and success stories replication to target countries (Morocco and Jordan) in order to establish or upgrade the advanced textile centers. Overall, the proposed teaching and e-learning methods and the aspects of the need for training and EU best practices implementation and success stories replication to target countries (Morocco and Jordan) in order to establish or upgrade the advanced textile centers are essential for higher education organizations involved. In the framework of the FOSTEX Erasmus+ project were identified the best practices across Europe with high potential for being transferrable to the partner countries (Morocco and Jordan) including aspects concerning learning, teaching (courses), dissemination, quality testing, international standardization, equipment, and research projects. We can conclude that the interest of the partners is focused on polymers, protective clothing tests, colour management, product certification, international accreditation, environmental impact (Reach Legislation), colour fastness, washing fastness, and physico-mechanical investigation.
\end{abstract}

Keywords: textile, learning, quantitative, qualitative

\section{INTRODUCTION}

In the framework of the FOSTEX Erasmus+ project, some crucial activities were to identify and analyze EU best practices and successful experiences to be transferred to target countries (Morocco and Jordan) and an electronic database. The database contains best practices identified across Europe with high potential for being transferrable to the partner countries (Morocco and Jordan) and successful EU funded project experiences in capacity building from different sectors. Good practice examples include aspects concerning learning, teaching (courses), dissemination, quality testing, standardization, equipment acquisition, educational, and research projects. The best practices' objectives are to promote research and projects between EU and Moroccan and Jordanian universities in the advanced textiles sector and to create useful research innovation and training network that will continue to generate sustainable results after the end of the project.

However, teaching and learning methods are useful to enhance the educational level of the students. The learning methods to be used (formal or informal type) are necessary for establishing adequate tools and techniques to be used in classes. However, learning in advanced textile materials is the process of acquiring new or modifying existing knowledge, behaviors, skills that can be achieved by examples, theories, and practical examples. Another challenge was to create a training Toolkit for the capacity building consisting of slides, images, and further readings, exercises for each topic covered customized for Jordanian and Moroccan partners' needs.

In order to develop the new advanced textile centers, it is vital to improving the knowledge level through seminars, workshops, e-learning and training, and the infrastructures by the development of new research centers (Jordan), upgrading the existent research centers (Morocco) with new high-quality equipment for material testing, and by promoting the quality in textile materials testing by use of the adequate standards, methods, procedures, and equipment. 
Good practices are lessons already learned about specific aspects concerning teaching, mentoring, dissemination, providing skills, knowledge transfer, coaching for fostering the capacity building in the partner countries (Morocco and Jordan).

In general, the FOSTEX project aims to fill the gap in the area of specialized services for the textile sector, with the establishment of two Textile Centres in Universities of Jordan and the upgrade of two Textile Centres in Morocco through novel and upgraded services such as quality testing, certification of products, human resources training, support of participation to informative seminars, workshops, exhibitions; investigation in the organization of efficient production and enhancing entrepreneurship and integration of refugees into the textile sector; searching for funding opportunities, and improving the textile industry's ability to meet unexpected challenges and to turn into opportunities such as creating protective equipment against COVID-19.

\section{TRAINING TOOLKIT}

In the framework of the FOSTEX Erasmus+ project, have been created a toolkit containing knowledge useful in setting the new textile centers or in upgrading the existing ones and also for applicative and fundamental research investigations.

Among existing testing methods that can be used in textile applicative research or industrial investigation have been selected for the courses, only the methods related to tensile strength testing (Wu and Pan, 2005), testing for protective equipment, washing colour fastness, and colour fastness testing.

The tensile strength testing course module describes the available two methods such as grab (ISO 13934-2:2013, ISO 13935-2:2014) and strip (ISO 13934-1:2013, ISO 13935-1:2014) methods used for tensile strength testing. The strip and grab methods are mainly applicable to woven textile fabrics, fabric containing elastomeric fiber, mechanical or chemical treatment. However, usually, strip and grab methods do not apply to geotextiles, nonwovens, coated fabrics, textile-glass woven fabrics, and fabrics made from carbon fibers or polyolefin tape yarns. Using the strip and grip methods can be investigated the maximum force and elongation at maximum force of test specimens in equilibrium with the standard atmosphere for testing, and test specimens in the wet condition.

The testing for protective textiles and accessories course module highlighted the aspects concerning the technical textiles used to protect against hazards.

The hazard is defined as a situation that can be the cause of harm or damage to the health of the human body. In addition, the hazards types (mechanical, chemical, cold, heat and/or fire, biological agents, radiation) are considered the risks as a combination of the frequency/probability, of occurrence and the consequence of a specified hazard, and the protective textile performance level a number that designates a particular category or range of performance by which the results of testing can be graded.

In the scientific literature are defined several classifications of protective textiles (Raheel, 1994) such as:

- the protection of wearers and/or textiles against insects (Hipler and Elsner, 2006);

- the protection of wearers and/or textiles against heat and fire protection (Horrocks, 2005; Horrocks, 2014; Lawrence, 2014) (firefighters);

- the protection of wearers to water and/or waterproof textiles (water protection) (Türk, 2015);

- the protection of wearers against biological agents (Endrusick et al., 2005);

https://doi.org/10.24264/icams-2020.VI.1 
- the radiance protection of wearers against ultraviolet (UV) rays of the sun (Gies et al., 1998; Ranjan Das, 2010);

- the protection of wearers and/or textiles against electromagnetic-waves (Maity et al., 2013; Koch, 2003) (shielding effect);

- the protection of soldiers and/or textiles for military applications (Wilusz, 2008) against chemical (Anna, 2003), biological, radiological, and nuclear (CBRN) (Magalhães et al., 2017) warfare threats.

Colour fastness-testing represents the resistance testing of the colour of textiles to the different agents (figure 1) to which these materials may be exposed during manufacture and wearing. However, the most used colour fastness tests in the textile industry are color fastness to wash, to rubbing, to perspiration, to light, and hot pressing.

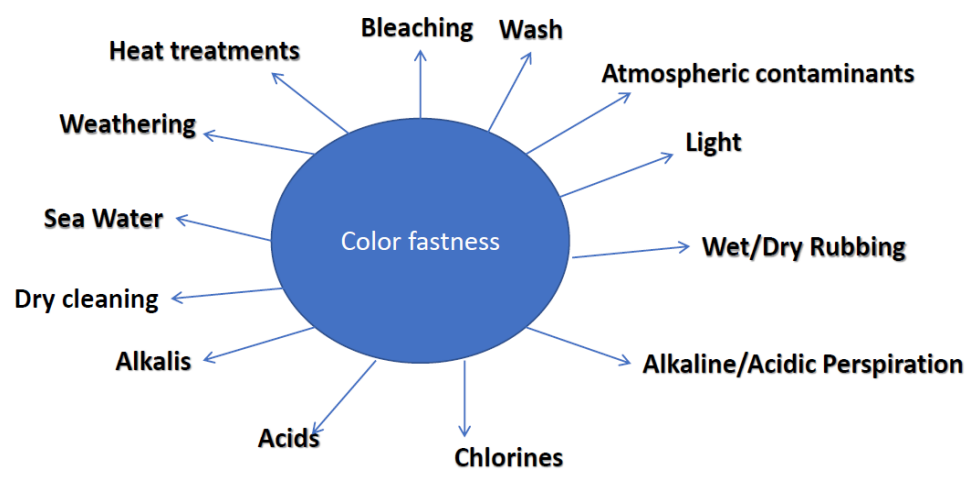

Figure 1. Types of color fastness testing -according ISO 105-A01:2010

In the case of the investigations more appropriate to fundamental research, we can mention the elemental and molecular analysis (Table 1 - Robinson, 2014) used for analysis that can be performed, often with the same instrument and may use light interaction, heat interaction, electric fields or magnetic fields. Each one elemental or molecular analysis uses methods such as:

$\rightarrow$ Qualitative methods that provide information about the identity of atomic/molecular species and functional groups of the sample;

$\rightarrow$ Quantitative methods that provide numerical information about the relative amount of one or more components.

Table 1. Instrumental methods of analysis (Robinson, 2014)

\begin{tabular}{lcccc}
\hline \multicolumn{1}{c}{ Method } & \multicolumn{2}{c}{ Quantitative } & \multicolumn{2}{c}{ Qualitative } \\
& Elemental & Molecular & Elemental & Molecular \\
\hline Atomic absorption spectrometry (AAS) & No & No & Yes & No \\
Atomic emission spectrometry (AES) & Yes & No & Yes & No \\
Capillary electrophoresis (CE) & Yes & Yes & Yes & Yes \\
Gas chromatography (GC) & No & Yes & No & Yes \\
ICP-mass spectrometry (ICP-MS) & Yes & No & Yes & No \\
IR spectroscopy & No & Yes & No & Yes \\
Ion chromatography (IC) & Yes & Yes & Yes & Yes \\
Liquid chromatography (LC) & No & Yes & No & Yes \\
Mass spectroscopy (MS) & Yes & Yes & Yes & Yes \\
Nuclear magnetic resonance (NMR) & No & Yes & No & Yes \\
\hline
\end{tabular}

https://doi.org/10.24264/icams-2020.VI.1 
Fostering Advanced Textile Centers through E-Learning in Morocco and Jordan

\begin{tabular}{lcccc}
\hline \hline \multicolumn{1}{c}{ Method } & \multicolumn{2}{c}{ Quantitative } & \multicolumn{2}{c}{ Qualitative } \\
& Elemental & Molecular & Elemental & Molecular \\
\hline Raman spectroscopy & No & Yes & No & Yes \\
Thermal analysis (TA) & No & Yes & No & Yes \\
UV/VIS spectrophotometry & Yes & Yes & Yes & Yes \\
UV absorption & No & Yes & No & Yes \\
UV fluorescence & No & Yes & No & Yes \\
X-ray absorption (XAS) & Yes & No & Yes & No \\
X-ray diffraction (XRD) & No & Yes & No & Yes \\
X-ray fluorescence (XRF) & Yes & No & Yes & No \\
\hline
\end{tabular}

In the case of the quality testing course module, the adopted approach was to specify the essential terms, definitions, and standards applied in quality (ISO 9000:2015; ISO 9001:2015; ISO 9004:2018), the general terms and definitions relating to conformity assessment to facilitate trade (ISO/IEC 17000:2020), and the general requirements for the competence, impartiality and consistent operation of laboratories (ISO/IEC 17025:2017).

The course module concerning international conformity assessment provided a clear explanation of the certification as a useful tool to add credibility by demonstrating that the product, service, or system meets the expectations of the customers. However, the certification is also known as third party conformity assessment (testing, inspection, and certification) and is essential because, for some industries, certification is a legal or contractual requirement. International Certificate of Conformity $(\mathrm{CoC})$, also named Certificate of Compliance (Amutha, 2017), is a mandatory document necessary for Customs clearance of exports to many countries around the globe. International $\mathrm{CoC}$ is a document certified by a competent authority that the supplied good or service meets the required specifications. Also, the active companies from the textile industry must comply with environmental legislation REACH (Regulation (EC) 1907/2006) designed to ensure a high level of protection of human health and the environment and to manage and control the potential risk to human health and the environment due to the use of chemicals in the European Union.

At the end the all requirements of the textile product (cleaning/washing instructions, size, composition, comfort requirements/specification, physic, chemical, mechanical or electrical requirements/parameters) should be integrated into the technical specification sheet, and some of the information above mentioned should be included in the label, or a hangtag with a barcode.

\section{CONCLUSIONS}

The proposed Training Toolkit is composed of training materials with the necessary technical support relating to the online teaching methods, lesson content, and practical information of the training program. During the online courses was observed an increased interest in lessons related to protective textiles, instrumental analysis, and colour fastness testing. Besides, the participants were very interested in new technologies used for functionalization (plasma) and creating 3D composite materials based textile supports and using polymer matrix and metal microparticles, 3D printing, microwave, and plasma pretreatments. 


\section{REFERENCES}

Amutha, K. (2017), "Sustainable Practices in Textile Industry: Standards and Certificates", in: Sustainability in the Textile Industry, pp. 79-107, Springer, Singapore, https://doi.org/10.1007/978-981-10-2639-3_5.

Anna, D.H. (ed.) (2003), Chemical protective clothing, AIHA, https://doi.org/10.3320/978-1-931504-46-1.

Endrusick, T.L., Gonzalez, J.A. and Gonzalez, R.R. (2005), "Improved comfort of US military chemical and biological protective clothing", Environmental Ergonomics, 3, pp. 369-373, https://doi.org/10.1016/S1572-347X(05)80058-8.

Gies, P.H., Roy, C.R., Toomey, S. and McLennan, A. (1998), "Protection against solar ultraviolet radiation", Mutation Research/Fundamental and Molecular Mechanisms of Mutagenesis, 422(1), pp.15-22, https://doi.org/10.1016/S0027-5107(98)00181-X.

Hipler, U.C. and Elsner, P. (eds.) (2006), Biofunctional textiles and the skin, Vol. 33, Karger Medical and Scientific Publishers, https://doi.org/10.1159/isbn.978-3-318-01349-8.

Horrocks, A.R. (2005), Thermal (heat and fire) protection. Textiles for protection, pp.411-423, Elsevier, https://doi.org/10.1201/9781439823811.ch15.

Horrocks, A.R. (2014), "High performance textiles for heat and fire protection", in: High Performance Textiles and their Applications, pp. 144-175, Woodhead Publishing, https://doi.org/10.1533/9780857099075.144.

ISO 105-A01:2010, Textiles — Tests for colour fastness — Part A01: General principles of testing.

ISO 13934-1:2013, Textiles — Tensile properties of fabrics — Part 1: Determination of maximum force and elongation at maximum force using the strip method

ISO 13934-2:2014, Textiles — Tensile properties of fabrics — Part 2: Determination of maximum force using the grab method.

ISO 13935-1:2014, Textiles — Seam tensile properties of fabrics and made-up textile articles — Part 1 : Determination of maximum force to seam rupture using the strip method.

ISO 13935-2:2014, Textiles — Seam tensile properties of fabrics and made-up textile articles — Part 2: Determination of maximum force to seam rupture using the grab method.

ISO 9000:2015, Quality management systems — Fundamentals and vocabulary.

ISO 9001:2015, Quality management systems — Requirements.

ISO 9004:2018, Quality management — Quality of an organization — Guidance to achieve sustained success

ISO/IEC 17000:2020, Conformity assessment - Vocabulary and general principles.

ISO/IEC 17025:2017, General requirements for the competence of testing and calibration laboratories.

Koch, M., Autoflug GmbH (2003), "Textile base material having an electromagnetic wave shielding", U.S Patent Application 10/448,979.

Lawrence, C. (ed.) (2014), High performance textiles and their applications, Elsevier.

Magalhães, M.J., de Magalhães, S.T., Revett, K. and Jahankhani, H. (2017), "Chemical, Biological, Radiological and Nuclear (CBRN) protective clothing-A review", International Conference on Global Security, Safety, and Sustainability, pp. 331-341, Springer, Cham, https://doi.org/10.1007/978-3-319. 51064-4_26.

Maity, S., Singha, K., Debnath, P. and Singha, M. (2013), “Textiles in electromagnetic radiation protection. Journal of Safety Engineering, 2(2), pp.11-19.

Raheel, M. (ed.) (1994), Protective clothing systems and materials, Vol. 25, CRC Press

Ranjan Das, B. (2010), "UV radiation protective clothing", The Open Textile Journal, 3(1).

Robinson, J.W., Frame, E.S. and Frame II, G.M. (2014), Undergraduate instrumental analysis, CRC press, https://doi.org/10.1201/b15921.

Türk, M., Ehrmann, A. and Mahltig, B. (2015), "Water-, oil-, and soil-repellent treatment of textiles, artificial leather, and leather", The Journal of The Textile Institute, 106(6), pp.611-620, https://doi.org/10.1080/00405000.2014.931108.

Wilusz, E. (ed.) (2008), Military textiles, Elsevier, https://doi.org/10.1201/9781439833247.

Wu, J. and Pan, N. (2005), "Grab and strip tensile strengths for woven fabrics: An experimental verification", Textile research journal, 75(11), pp.789-796, https://doi.org/10.1177/0040517505057525. 
Fostering Advanced Textile Centers through E-Learning in Morocco and Jordan

https://doi.org/10.24264/icams-2020.VI.1 